Revista Brasil. Bot., V.31, n.3, p.443-452, jul.-set. 2008

\title{
Variabilidade morfológica foliar de Miconia sellowiana (DC.) Naudin (Melastomataceae) em diferentes fitofisionomias no Estado do Paraná ${ }^{1}$
}

\author{
MARIA REGINA TORRES BOEGER ${ }^{2,4}$, RENATA MARIA GLUZEZAK ${ }^{2}$, \\ MARIA WILHELMINA PIL ${ }^{2}$, RENATO GOLDENBERG ${ }^{2}$ e MOACYR MEDRI ${ }^{3}$
}

(recebido: 04 de outubro de 2007; aceito: 12 de junho de 2008)

\begin{abstract}
Leaf morphology variation of Miconia sellowiana (DC.) Naudin (Melastomataceae) in distinct vegetation types at the state of Paraná). This study investigated the leaf morphology of Miconia sellowiana, in four different vegetation types: Grassland (EGL), Montane Atlantic Forest (FODM), Upper Montane Atlantic Forest (FODAM), and Araucaria Forest (FOM), at the state of Paraná, Brazil. Twenty leaves were selected from six individuals from each vegetation type. Several leaf parameters were analyzed including leaf area, leaf dry mass, specific leaf area (SLA), trichomes and stomata densities, and anatomical measurements. The leaves of M. sellowiana from EGL and FODAM presented pronounced xeric characteristics, with higher mean values for stomata density, trichome density on the adaxial surface, thickness of the cuticle of adaxial epidermis, spongy parenchyma, and total lamina thickness; and lower mean values for leaf area, dry leaf mass, and specific leaf area. The use of ANOVA and PCA detected a mesophylly-to-xeromorphy gradient among the four vegetation types: FOM>FODM>EGL>FODAM. The differences are apparently associated to several environmental conditions, mainly soil characteristics and light intensity.
\end{abstract}

Key words - leaf morphology, Miconia sellowiana

RESUMO - (Variabilidade morfológica foliar de Miconia sellowiana (DC.) Naudin (Melastomataceae) em diferentes fitofisionomias no Estado do Paraná). Este estudo investigou a morfologia foliar de Miconia sellowiana, ocorrente em quatro diferentes fitofisionomias: Estepe Gramíneo-Lenhosa (EGL), Floresta Ombrófila Densa Montana (FODM), Floresta Ombrófia Mista (FOM) e Floresta Ombrófila Densa Alto-Montana (FODAM), no Estado do Paraná, Brasil. Ramos de seis indivíduos de cada fitofisionomia foram coletados, sendo selecionadas 20 folhas por indivíduo. A área foliar, massa seca foliar, área foliar específica, densidades de tricomas e de estômatos, espessura da cutícula, espessura total e dos tecidos da lâmina foliar foram analisados. As características morfológicas foliares variaram significativamente para os parâmetros analisados. As folhas de M. sellowiana da EGL e FODAM apresentaram características mais xeromórficas, com os maiores valores médios para densidade estomática e de tricomas, maiores espessuras da cutícula da face adaxial, do parênquima esponjoso e espessura total da lâmina e os menores valores médios para a área e massa seca foliar e área foliar específica. A análise de variância e a análise dos componentes principais detectaram um gradiente de mesofilia/xeromorfia entre as quatro fitofisionomias: FOM >FODM $>$ EGL $>$ FODAM. Aparentemente, as diferenças encontradas estão associadas com vários fatores ambientais, principalmente com as características do solo e a intensidade luminosa.

Palavras-chave - Miconia sellowiana, morfologia foliar

\section{Introdução}

A estrutura das plantas é comumente afetada pelos diversos fatores ambientais e as variações resultantes desta interação são expressas na sua morfologia e anatomia. As plantas respondem à disponibilidade de luz e água, concentração de nutrientes no solo, tipo de relevo, altitude, clima, entre outros. A influência destes

1. Parte da dissertação de Mestrado da segunda autora, Universidade Federal do Paraná, Programa de Pós-Graduação em Botânica.

2. Universidade Federal do Paraná, Setor de Ciências Biológicas, Departamento de Botânica, Centro Politécnico, Caixa Postal 19031, 81531-990 Curitiba, PR, Brasil.

3. Universidade Estadual de Londrina, Centro de Ciências Biológicas, Departamento de Biologia Animal e Vegetal, Caixa Postal 6001, 86051-990 Londrina, PR, Brasil.

4. Autor para correspondência: rboeger@ufpr.br fatores ambientais contribui para a grande diversidade vegetal e, conseqüentemente, para a distribuição das espécies nos diferentes biomas (Dickison 2000).

A folha é considerada o órgão da planta que mais apresenta variações estruturais (Lewis 1972, Marques et al. 1999) e as alterações foliares têm sido estudadas como indicadoras ambientais (Dickison 2000). Além disso, a folha é um dos mais importantes órgãos da planta, responsável por inúmeras de suas funções vitais. Isto ocorre devido à área do limbo exposta diretamente aos raios luminosos e à absorção de dióxido de carbono, ambos essenciais para os processos fotossintéticos (Lewis 1972, Taiz \& Zeiger 2004).

Sob influência de diferentes fatores ambientais, muitas espécies de plantas desenvolvem diversas estratégias, representadas por características morfológicas, anatômicas 
e fisiológicas, para se manterem e se propagarem nos mais variados ambientes (Sultan 2003). As características morfológicas das plantas são geneticamente determinadas, mas também podem ser fortemente influenciadas pelo meio ambiente como uma forma de adaptação, sendo que a interação de efeitos genéticos e ambientais atua conjuntamente para modelar o fenótipo (Schlichting 2002).

As espécies com grande potencial de plasticidade para caracteres ligados à sobrevivência apresentam vantagens adaptativas em ambientes instáveis, heterogêneos ou de transição, visto que as mudanças produzidas podem facilitar a exploração de novos nichos, resultando no aumento da tolerância ambiental (Via \& Lande 1985). Espera-se que plantas que ocupam ambientes heterogêneos apresentem um grande potencial plástico em suas características fisiológicas e/ou morfológicas (Fuzeto \& Lomônaco 2000).

Miconia sellowiana (DC.) Naudin é uma planta pioneira (ou secundária inicial) e heliófita facultativa, com ampla distribuição no Estado do Paraná, Brasil. Seus representantes geralmente ocorrem em altitudes de 1.000 a $2.000 \mathrm{~m}$ e, raramente, ao nível do mar. Pode ser encontrada com hábito arbóreo, atingindo até oito metros de altura, em formações florestais secundárias, perenifólias ou semidecíduas ou ainda em cerrado, ou com hábito arbustivo, com menos de um metro de altura, em afloramentos rochosos. Apresenta uma grande variabilidade morfológica, principalmente no que se refere à forma das folhas e à densidade de tricomas nos ramos jovens e folhas
(Goldenberg 2004). Estudos efetuados em populações em Corumbataí, São Paulo, mostraram a ocorrência de apomixia nesta espécie (Saraiva et al. 1996).

Este trabalho investigou a variação natural da morfologia foliar de Miconia sellowiana (Melastomataceae), em quatro diferentes fitofisionomias (Estepe GramíneoLenhosa; Floresta Ombrófila Densa Montana, Floresta Ombrófila Densa Alto-Montana e Floresta Ombrófila Mista), no Estado do Paraná, buscando avaliar a influência dos diferentes fatores ambientais sobre a sua estrutura foliar.

\section{Material e métodos}

As plantas foram coletadas em quatros diferentes fitofisionomias cujas características de cada ambiente são apresentadas na tabela 1 .

a) Estepe Gramíneo-Lenhosa (EGL): o parque Buraco do Padre localiza-se na Fazenda "Nasce o Dia", município de Ponta Grossa, PR, no Planalto dos Campos Gerais, com uma área de 69 ha (Swiech-Ayoub \& Masunari 2001). A vegetação é classificada como Estepe Gramíneo-Lenhosa, com plantas herbáceas e arbustivas crescendo sobre afloramentos rochosos, principalmente em frestas com acúmulo de matéria orgânica e inorgânica. Miconia sellowiana ocorre na forma arbustiva, com altura de 0,5 a $2,0 \mathrm{~m}$.

b) Floresta Ombrófila Densa Montana (FODM): o Parque Estadual dos Mananciais da Serra, de propriedade do Governo Estadual, sob jurisdição da Sanepar, localiza-se na Serra do Mar, município de Piraquara, PR, com uma área

Tabela 1. Quadro comparativo das características ambientais das quatro fitofisionomias. (EGL = Estepe Gramíneo Lenhosa; FODM = Floresta Ombrófila Densa Montana; FOM = Floresta Ombrófila Mista; FODAM = Floresta Ombrófila Densa Alto Montana).

Table 1. Comparison of environmental features from four vegetation types. (EGL = Grassland; FODM = Montane Atlantic Forest; FOM = Araucaria Forest; FODAM = Upper Montane Atlantic Forest).

\begin{tabular}{lcccc}
\hline Características ambientais & FODAM & EGL & FODM & FOM \\
\hline Latitude & $25^{\circ} 30^{\prime} \mathrm{S}$ & $25^{\circ} 0^{\prime}, \mathrm{S}$ & $25^{\circ} 29^{\prime} \mathrm{S}$ & $25^{\circ} 30^{\prime} \mathrm{S}$ \\
Longitude & $48^{\circ} 59^{\prime} \mathrm{W}$ & $49^{\circ} 58^{\prime} \mathrm{W}$ & $49^{\circ} 59^{\prime} \mathrm{W}$ & $49^{\circ} 50^{\prime} \mathrm{W}$ \\
Temperatura média anual $\left({ }^{\circ} \mathrm{C}\right)$ & 17,2 & 17,8 & 16,6 & 18 \\
$\left(\right.$ mínima - máxima, $\left.{ }^{\circ} \mathrm{C}\right)$ & $(18-22)$ & $(14,1-20,9)$ & $(13-20,6)$ & $(13-24)$ \\
Precipitação média anual $(\mathrm{mm})$ & $1.321,3$ & 1.497 & 2.500 & 1.451 \\
Clima & $\mathrm{C} f \mathrm{~B}$ & $\mathrm{C} f \mathrm{~B}$ & $\mathrm{C} f \mathrm{~B}$ & $\mathrm{C} f \mathrm{~B}$ \\
Solo & Neossolo litólico & Neossolo litólico & Neossolo litólico & Cambissolo Háplico \\
& Húmico típico & Distrófico típico & Húmico típico & Alumínico típico \\
& & Tb A proeminente & Tb hipodistrófico & \\
Altitude $(m)$ & & & e álico & 900 \\
Umidade média relativa do ar $(\%)$ & 1.370 & 975 & 1.100 & 91 \\
\hline
\end{tabular}


de 2.249 ha (Cáceres 2004). Grande parte da área do Parque é revestida por Floresta Ombrófila Densa Montana (Cáceres 2004). Este tipo de fitofisionomia corresponde no sul do País às florestas que se situam entre 500 e $1.500 \mathrm{~m}$ de altitude (IBGE 1992), onde o relevo mais suave apresenta solos mais profundos e uma formação florestal que pode atingir, em média, 20 a $25 \mathrm{~m}$ de altura distribuída em três ou mais estratos arbóreos com muitas epífitas e lianas. Miconia sellowiana ocorre na forma arbórea, nos estratos inferiores da floresta, com altura em torno de 2,0 a 4,0 m.

c) Floresta Ombrófila Alto-Montana (FODAM): o Morro do Canal localiza-se na Serra do Marumbi, no município de Piraquara, na porção leste da Região Metropolitana de Curitiba, PR, com uma área de 2.456 ha. O Morro do Canal ocorre numa área de transição entre a Serra do Mar e o Primeiro Planalto. A estrutura da vegetação é integrada por fanerófitos com troncos e galhos finos, além de lianas lenhosas e epífitas em abundância, apresentando acumulações turfosas nas depressões (Veloso et al. 1991). Miconia sellowiana ocorre na forma arbustiva, em áreas abertas onde o relevo permitiu o acúmulo de matéria orgânica, com altura variando de de 1,3 a 2,3 m.

d) Floresta Ombrófila Mista (FOM): a Fazenda Experimental do Canguiri, da Universidade Federal de Paraná, localiza-se no município de Pinhais, PR, com uma área de 430 ha (Donha 2003). A vegetação predominante na área é a Floresta Ombrófila Mista, constituída por dois estratos arbóreos e caracterizada pela presença da Araucaria angustifolia, que ocupa o estrato arbóreo superior (Klein 1984). Miconia sellowiana ocorre na forma arbórea, nos estratos inferiores da floresta, podendo atingir $8 \mathrm{~m}$ de altura.

Os dados climáticos foram obtidos para o ano de 2006, junto ao Instituto Tecnológico Simepar, em duas estações meteorológicas próximas aos locais de coleta: uma na cidade de Ponta Grossa, PR, próximo ao parque Buraco do Padre (EGL) e outra na cidade de Pinhais, próxima ao Morro do Canal, Parque Estadual dos Mananciais da Serra e Fazenda Experimental do Canguiri. De acordo com os dados obtidos para o ano de 2006, os meses mais secos corresponderam de abril a junho. O solo da cada área, com exceção da FOM, foi coletado por meio de tradagem, com trado do tipo holandês ao redor das plantas cujas folhas foram coletadas. A classificação do solo seguiu a metodologia adotada pela Embrapa (1999). Para o solo da FOM, utilizou-se a análise realizada por Donha (2003).

Em cada fitofisionomia foram coletados ramos de seis indivíduos, sob a mesma condição de luz. As folhas de todos os indivíduos, nas quatro fitofisionomias, foram coletadas no mês de abril de 2006 e apresentaram diferenças morfológicas (figura 1). Os indivíduos selecionados, em cada fisionomia, estavam a uma distância mínima de $50 \mathrm{~m}$ entre si. De cada indivíduo, foram selecionadas 20 folhas, totalizando 120 folhas por fitofisionomia. As folhas foram coletadas entre o quarto e o sexto nós, no sentido ápice-base. Para a análise da morfologia foliar, 16 folhas de cada indivíduo foram prensadas e secas em estufa à temperatura de $65^{\circ} \mathrm{C}$ até atingirem peso constante. Para estas folhas, a massa seca (g) foi estimada em balança analítica de precisão Modelo AS 210 Scientech; a área foliar $\left(\mathrm{cm}^{2}\right)$ calculada a partir de imagem digitalizada em scanner de mesa, acoplado ao computador, pelo programa SIGMASCAN-PRO (versão 4.0, SPSS Inc., Chicago, IL, USA, 1995) e a área foliar específica (AFE = área foliar $\left(\mathrm{cm}^{2}\right)$; massa seca foliar $\left.{ }^{-1}(\mathrm{~g})\right)$.

A densidade estomática e de tricomas $\left(\mathrm{n} \mathrm{mm}^{-2}\right)$ foi efetuada utilizando-se a modelagem da epiderme na região mediana da folha com esmalte de unha sintético incolor. As modelagens foram montadas entre lâmina e lamínula com água e as densidades estomáticas e de tricomas foram estimadas por meio de contagem numa área de $1 \mathrm{~mm}^{2}$. Utilizou-se 2 campos por folha, para 96 folhas totalizando 192 campos para cada fitofisionomia. Os estômatos foram contados apenas na epiderme da face abaxial, por se tratar de uma folha hipoestomática. As contagens foram realizadas em microscópio de luz Olympus CBB, com câmara clara acoplada.

Para as lâminas semipermanentes, o material vegetal, após fixação em FAA em etanol $50 \%$, foi seccionado transversalmente com lâmina de barbear, clarificado em hipoclorito de sódio $10 \%$, corado com azul de toluidina $1 \%$ solução aquosa, montado em gelatina glicerinada (O'Brien \& Mccully 1981) e vedado com esmalte de unha incolor. Para a medição das espessuras dos tecidos da lâmina foliar
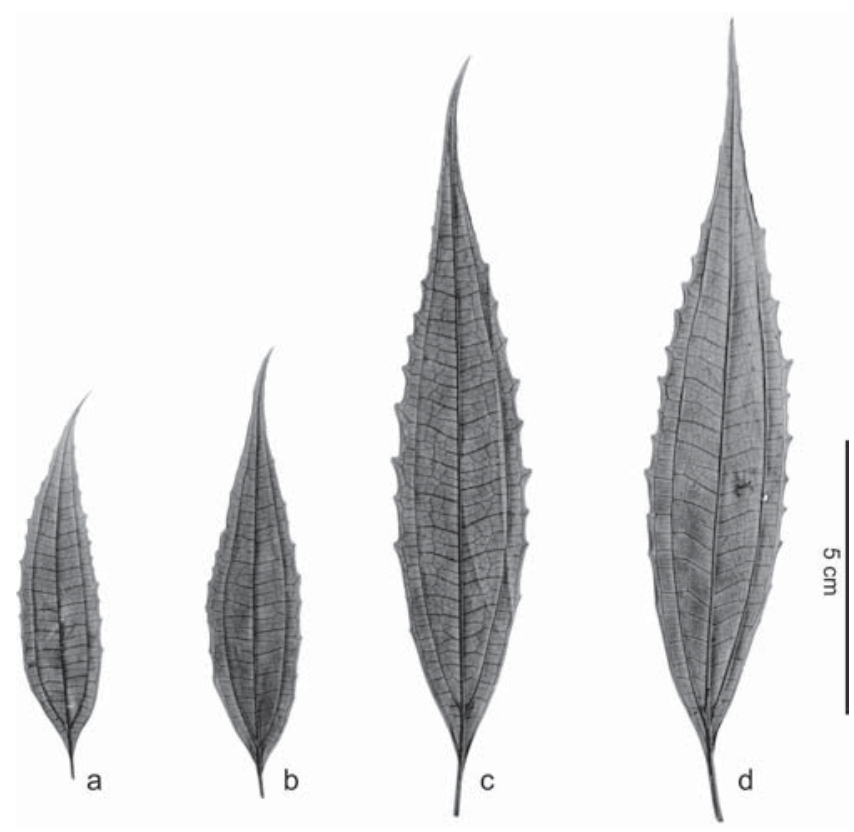

Figura 1. Aspecto da folha de Miconia sellowiana nas diferentes fitofisionomias. a. Floresta Ombrófila Mista. b. Floresta Ombrófila Densa Montana. c. Estepe-Gramíneo Lenhosa. d. Floresta Ombrófila Densa Alto-Montana.

Figure 1. Leaf features of Miconia sellowiana from different vegetation types. a. Araucaria Forest. b. Montane Atlantic Forest. c. Grassland. d. Upper Montane Atlantic Forest. 
$(\mu \mathrm{m})$ utilizou-se secções transversais da região mediana da folha, onde foi medida a espessura total da lâmina foliar, a espessura da cutícula das faces adaxial e abaxial da folha, a espessura da epiderme adaxial e da epiderme abaxial, espessuras dos parênquimas paliçádico e esponjoso. As medições foram realizadas em microscópio de luz Olympus CBB, com auxílio de ocular micrometrada.

As médias e respectivos erros-padrão de todas as variáveis quantitativas foram calculadas. A Análise de Variância (ANOVA) foi utilizada para comparar as folhas das plantas das quatro diferentes fitofisionomias, através do Programa Statistica versão 6.0 (StatSoft, Inc., Tulsa, OK, USA 1998). Para cada variável, verificou-se a diferença significativa entre as fitofisionomias, utilizando-se o teste de comparação múltipla LSD (menor diferença significativa) de Fisher. A análise dos componentes principais (PCA) foi utilizada para descrever a maior variância entre algumas variáveis quantitativas estudadas, através do programa Past, versão 1.34 (Hammer et al. 2001).

\section{Resultados}

A análise de variância indicou que as características morfológicas quantitativas (área foliar, massa seca, densidade estomática e espessura do parênquima esponjoso) variaram significativamente entre as quatro fitofisionomias (tabela 2). As folhas das plantas da FOM apresentaram maior área foliar e massa seca foliar (tabela 2) quando comparadas com as folhas das demais fitofisionomias. As folhas de EGL apresentaram os maiores valores médios para densidade de tricomas da face adaxial e da face abaxial (tabela 2), além da espessura do parênquima paliçádico (tabela 3). As espessuras médias do parênquima esponjoso e a espessura da cutícula da face adaxial (tabela 3 ) assim como a densidade estomática média (tabela 2) foram maiores nas folhas da FODAM em relação às folhas das demais fitofisionomias.

Os valores médios de algumas características foram semelhantes apenas entre duas fitofisionomias como os valores médios da área foliar específica (AFE), densidade de tricomas da epiderme abaxial das folhas das plantas de FOM e da FODM, a densidade de tricomas da epiderme adaxial das folhas de FODAM e FOM (tabela 2), as espessuras da epiderme abaxial e do parênquima paliçádico para as folhas de FODAM e FODM, a espessura total da lâmina das folhas de EGL e FODAM e a espessura média da epiderme abaxial das folhas da FODAM e FODM (tabela 3).

A análise dos componentes principais (PCA) mostrou que os dois primeiros componentes (área foliar e densidade de tricomas da face abaxial) explicaram $82,71 \%$ da variância total. PC1 explicou $58,29 \%$ da variância e evidenciou a relação negativa entre área foliar com as densidades estomáticas e de tricomas e relação positiva com a massa seca. O PC2, representado principalmente pela densidade de tricomas da face adaxial, explicou $24,42 \%$ da variância e mostrou relação negativa com a densidade estomática e relação positiva com as demais variáveis (tabela 4). A figura 2 evidencia que para $\mathrm{PC} 1$ ocorrem dois agrupamentos, sendo um

Tabela 2. Valores médios e respectivos erros padrão (entre parênteses) das características morfológicas das folhas de Miconia sellowiana nas diferentes fitofisionomias $(n=96)$. Densidade estomática e densidade de tricomas $(n=192)$. Letras diferentes para a mesma variável representam valores estatisticamente diferentes (teste de Fisher, $P<0,05$ ). (EGL = Estepe Gramíneo Lenhosa; FODM = Floresta Ombrófila Densa Montana; FOM = Floresta Ombrófila Mista; FODAM = Floresta Ombrófila Alto Montana; AFE = área foliar específica).

Table 2. Mean values $( \pm$ SE) of morphological characteristics of leaves of Miconia sellowiana from different vegetation types $(n=96)$. Stomatal and trichome frequency $(n=192$ observations). Distinct letters in the same variable represent statistically different mean values. (Fisher's test, $P<0.05)$. (EGL = Grassland; FODM = Montane Atlantic Forest; FOM = Araucaria Forest; FODAM = Upper Montane Atlantic Forest; AFE = specific leaf area).

\begin{tabular}{lcccc}
\hline Características morfológicas & FODAM & EGL & FODM & FOM \\
\hline Área foliar $\left(\mathrm{cm}^{2}\right)$ & $3,51(0,09) \mathrm{d}$ & $4,33(0,14) \mathrm{c}$ & $7,55(0,24) \mathrm{b}$ & $10,77(0,46) \mathrm{a}$ \\
Massa foliar $\mathrm{g})$ & $0,0522(0,014) \mathrm{d}$ & $0,0616(0,020) \mathrm{c}$ & $0,0701(0,022) \mathrm{b}$ & $0,0876(0,018) \mathrm{a}$ \\
$\mathrm{AFE}\left(\mathrm{cm}^{2} \mathrm{~g}^{-1}\right)$ & $68,03(0,89) \mathrm{b}$ & $71,64(1,25) \mathrm{b}$ & $109,1(1,50) \mathrm{a}$ & $134,05(5,69) \mathrm{a}$ \\
$\begin{array}{l}\text { Densidade estomática }\left(\mathrm{n} \mathrm{mm} \mathrm{mm}^{-2}\right) \\
\text { Densidade de tricomas face } \\
\quad \text { adaxial }\left(\mathrm{n} \mathrm{mm}^{-2}\right)\end{array}$ & $1.383,64(26,92) \mathrm{a}$ & $1.133,2(11,64) \mathrm{b}$ & $769,54(11,71) \mathrm{c}$ & $556,34(9,87) \mathrm{d}$ \\
$\begin{array}{l}\text { Densidade de tricomas face } \\
\text { abaxial }\left(\mathrm{n} \mathrm{mm}^{-2}\right)\end{array}$ & $12,26(0,54) \mathrm{c}$ & $40,06(0,92) \mathrm{a}$ & $16,46(0,24) \mathrm{b}$ & $12,06(0,20) \mathrm{c}$ \\
\hline
\end{tabular}


Tabela 3. Valores médios e respectivos erros padrão (entre parênteses) das espessuras (em $\mu \mathrm{m}$ ) total e dos tecidos da lâmina foliar de Miconia sellowiana nas diferentes fitofisionomias $(n=12)$. Letras diferentes para a mesma variável significam que os valores são estatisticamente diferentes (teste de Fisher, $P<0,05)$. (EGL = Estepe Gramíneo Lenhosa; FODM = Floresta Ombrófila Densa Montana; FOM = Floresta Ombrófila Mista; FODAM = Floresta Ombrófila Alto Montana).

Table 3. Mean values $( \pm \mathrm{SE}$ ) of total lamina thickness and tissue thickness (in $\mu \mathrm{m})$ of leaves of Miconia sellowiana from different vegetation types $(n=12)$. Distinct letters in the same variable represent statistically different mean values. (Fisher's test, $P<0.05)$. $(\mathrm{EGL}=$ Grassland; FODM = Montane Atlantic Forest; FOM = Araucaria Forest; FODAM = Upper Montane Atlantic Forest).

\begin{tabular}{lcccc}
\hline Características anatômicas & FODAM & EGL & FODM & FOM \\
\hline Espessura cutícula da face adaxial & $6,15(0,62) \mathrm{a}$ & $4,18(0) \mathrm{b}$ & $2,09(0,00)^{*} \mathrm{c}$ & $2,09(0,00)^{*} \mathrm{c}$ \\
Espessura da epiderme adaxial & $10,71(0,69) \mathrm{ab}$ & $9,75(0,39) \mathrm{b}$ & $11,32(0,48) \mathrm{a}$ & $10,1(0,23) \mathrm{ab}$ \\
Espessura da epiderme abaxial & $8,73(0,61) \mathrm{a}$ & $6,79(0,27) \mathrm{b}$ & $8,01(0,24) \mathrm{a}$ & $6,79(0,27) \mathrm{b}$ \\
Esp. cutícula da face abaxial & $2,48(0,27) \mathrm{a}$ & $2,09(0,00)^{*} \mathrm{~b}$ & $2,09(0,00)^{*} \mathrm{~b}$ & $2,09(0,00)^{*} \mathrm{~b}$ \\
Espessura parênquima paliçádico & $45,62(3,33) \mathrm{b}$ & $64,09(4,01) \mathrm{a}$ & $48,42(3,62) \mathrm{b}$ & $23,69(1,49) \mathrm{c}$ \\
Espessura parênquima esponjoso & $108,89(7,72) \mathrm{a}$ & $77,5(2,95) \mathrm{b}$ & $47,18(2,51) \mathrm{c}$ & $35,7(1,49) \mathrm{d}$ \\
Espessura total da lâmina & $163,92(12,23) \mathrm{a}$ & $161,63(4,25) \mathrm{a}$ & $116,87(6,25) \mathrm{b}$ & $76,63(2,06) \mathrm{c}$ \\
\hline
\end{tabular}

*erro menor que último algarismo significativo / * error smaller than last significative algarism.

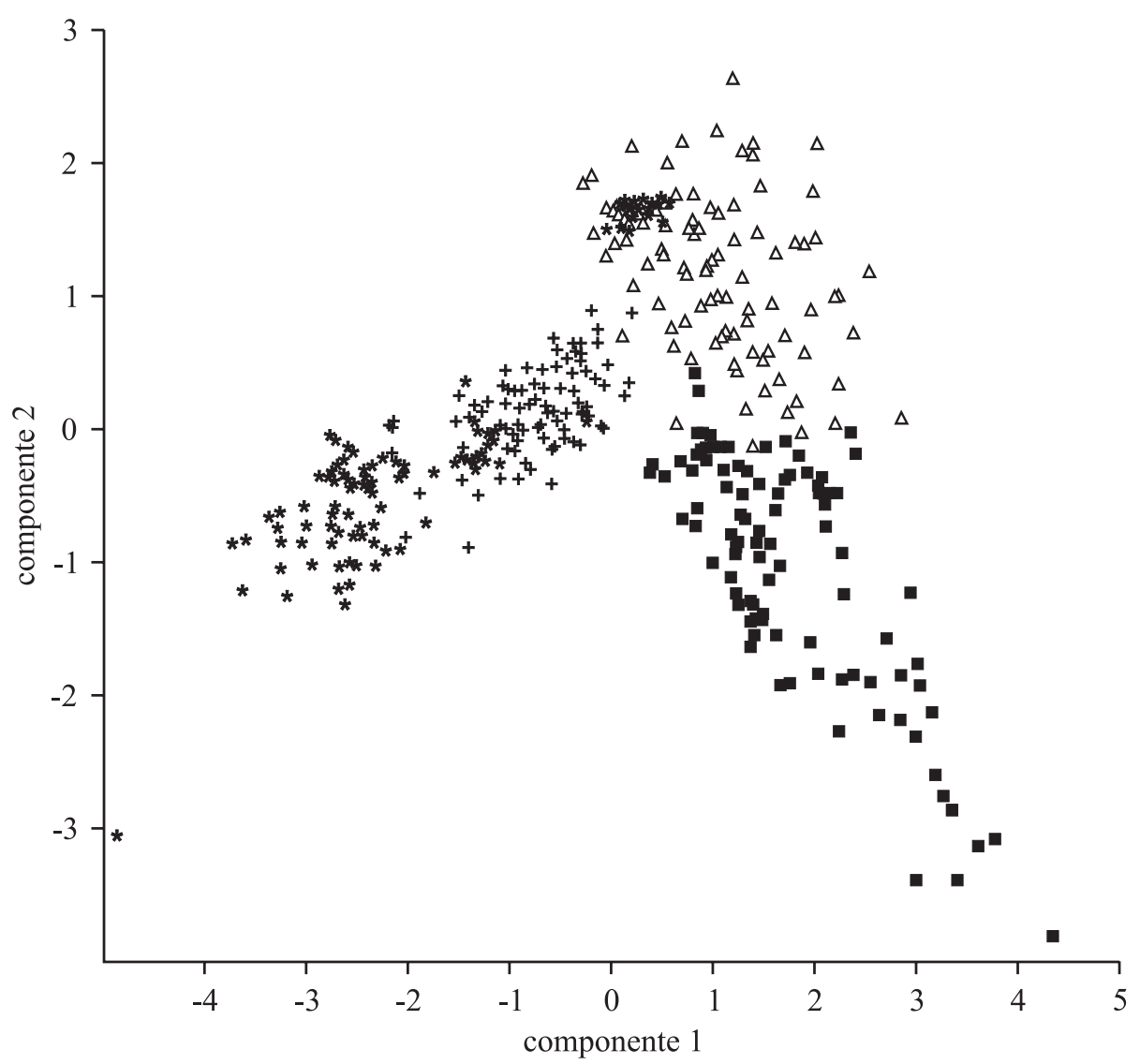

Figura 2. Análise de componentes principais (ACP) de uma matriz de correlação de características foliares de Miconia sellowiana. (ם = Estepe-Gramíneo Lenhosa; * = Floresta Ombrófila Mista; + = Floresta Ombrófila Densa Montana; $\Delta=$ Floresta Ombrófila Densa Alto-Montana).

Figure 2. Principal component analysis (PCA) of a correlation matrix of characteristics of Miconia sellowiana. ( $\mathbf{\square}=$ Grassland; * = Araucaria Forest $+=$ Montane Atlantic Forest; $\Delta=$ Upper Montane Atlantic Forest). 
Tabela 4. Peso das características das folhas das populações estudadas nos componentes 1 e 2 obtidos pela Análise de Componentes Principais.

Table 4. Weight of leaf characteristics from studied populations at components 1 and 2 obtained by Principal Component Analysis.

\begin{tabular}{lcc}
\hline \multirow{2}{*}{ Variáveis } & \multicolumn{2}{c}{ Componente Principal } \\
\cline { 2 - 3 } & & 2 \\
\hline Densidade de tricomas da & 0,84 & $-0,35$ \\
$\quad$ face abaxial & $-0,77$ & $-0,46$ \\
Área foliar & 0,76 & 0,48 \\
Densidade estomática & & \\
Densidade de tricomas da & 0,69 & $-0,64$ \\
$\quad$ face adaxial & $-0,05$ & $-0,09$ \\
Massa seca & & \\
Variância explicada pelos & 2,35 & 0,98 \\
$\quad$ componentes & & \\
Percentagem do total da & & \\
$\quad$ variância explicada & 58,29 & 24,42 \\
\hline
\end{tabular}

composto pelas folhas dos indivíduos de EGL e FODAM e um outro, formado pelas folhas dos indivíduos de FOM e FODM, devido a alta sobreposição dos pontos. Para PC2, a formação dos agrupamentos não é tão evidente.

A organização anatômica das folhas de M. sellowiana não variou entre as quatro fitofisionomias. Todas as folhas são hipoestomáticas e o mesofilo é organizado dorsiventralmente. Nas folhas das plantas da FOM e da FODM, o parênquima paliçádico varia de um a dois estratos de células e o parênquima esponjoso de três a cinco estratos de células (figuras 3 e 4). Nas folhas de EGL e FODAM, o parênquima paliçádico é composto de dois a três estratos de células e o parênquima esponjoso de cinco a seis estratos de células. Ainda nestas folhas, o parênquima esponjoso é mais compacto do que nas folhas das demais fitofisionomias. (figuras 5 e 6 ).

\section{Discussão}

A análise de variância indicou que as folhas de $M$. sellowiana diferiram significativamente entre as quatro
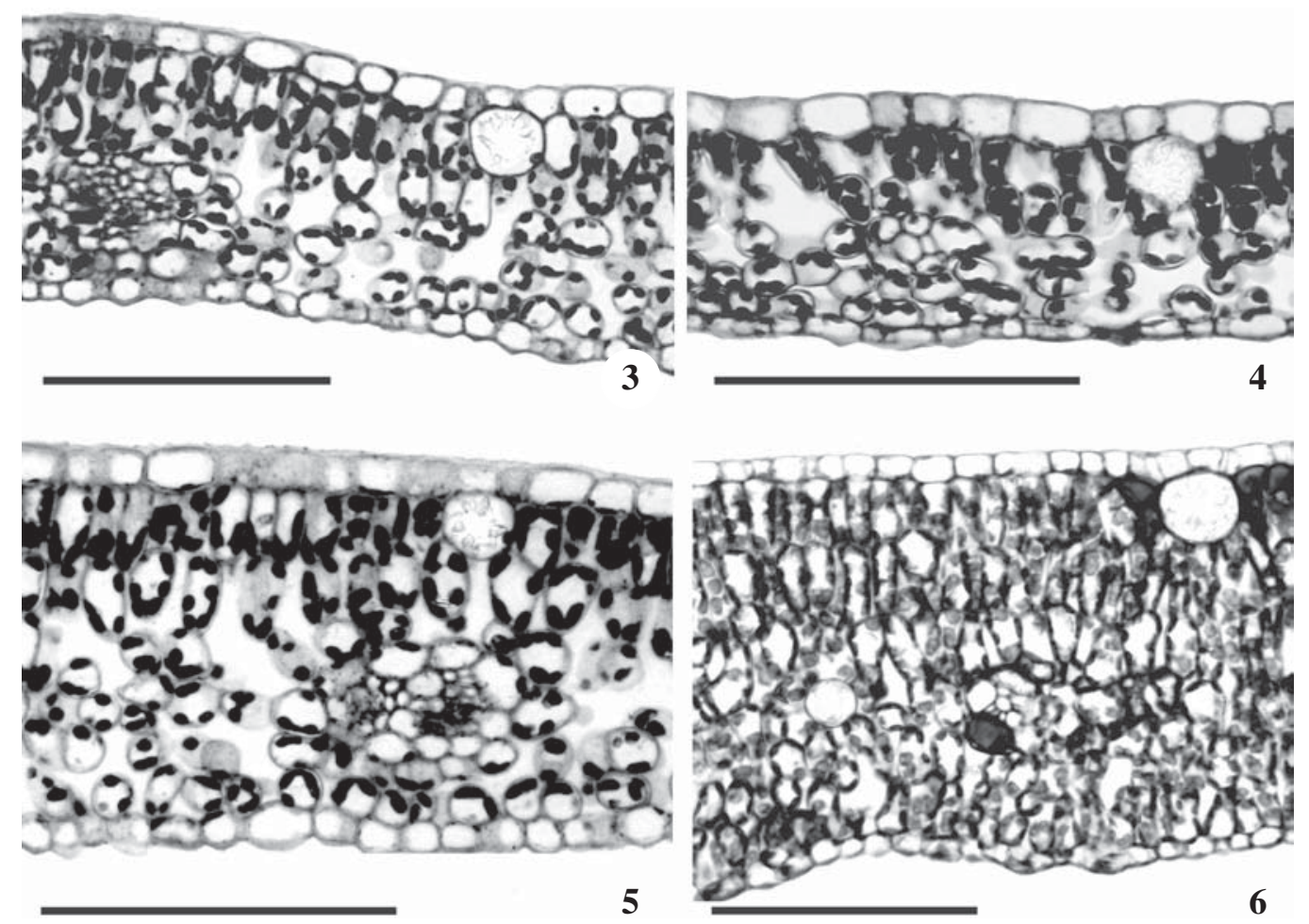

Figuras 3-6. Secções transversais do terço médio do mesofilo de Miconia sellowiana. 3. Floresta Ombrófila Mista. 4. Floresta Ombrófila Densa Montana. 5. Estepe-Gramíneo Lenhosa. 6. Floresta Ombrófila Densa Alto-Montana. Barra = $100 \mu$ m.

Figures 3-6. Transverse sections on the median region of the mesophyll of Miconia sellowiana. 3. Araucaria Forest. 4. Montane Atlantic Forest. 5. Grassland. 6. Upper Montane Atlantic Forest. Bar $=100 \mu \mathrm{m}$. 
fitofisionomias em relação a área foliar, massa seca, densidade estomática e espessura do parênquima esponjoso, enquanto que a análise dos componentes principais mostrou um gradiente entre as fitofisionomias, com a formação de dois agrupamentos, evidenciando uma similaridade morfológica entre as folhas de indivíduos de FOM e FODM e entre as folhas dos indivíduos de EGL e FODAM (figura 2).

As folhas dos indivíduos da FOM e FODM possuem as maiores áreas, massas foliares e maiores AFEs, menores densidades estomáticas e de tricomas da face abaxial, menores espessuras da lâmina, menores espessuras da cutícula da face abaxial e menores espessuras do parênquima esponjoso. As FOM e a FODM são fitofisionomias compostas por árvores de grande porte, distribuídas em vários estratos. O subosque é sombreado e o solo relativamente fértil, com maior capacidade de retenção de água. A pluviosidade elevada, associada à alta umidade relativa do ar, propicia maior disponibilidade de água para as plantas neste ambiente (tabela 1). Portanto, FODM e FOM apresentam condições ambientais mais mésicas que EGL e FODAM e isto se expressa na morfologia foliar. As condições ambientais da FODM e FOM propiciam maiores áreas foliares nos ambientes de subosques, característica essa associada à captação de luminosidade, pois quanto maior a área foliar, mais eficaz é a captura de luz, principalmente quando a umidade relativa do ar é alta. (Marques et al. 1999, Marques et al. 2000, Navas \& Garnier 2002, Sultan 2003). A maior massa seca das folhas dos indivíduos destas duas fitofisionomias, aparentemente, ocorre em função da maior área foliar, pois há pouca ocorrência de tecidos mecânicos.

A menor espessura foliar encontrada nas folhas dos indivíduos de FOM e FODM ocorre em função do menor número de estratos do parênquima paliçádico (um a dois estratos) e do parênquima esponjoso (três a seis estratos), conforme esperado. No entanto, esperava-se também que as folhas dessas duas fitofisionomias apresentassem espessuras bem maiores de parênquima esponjoso em relação ao parênquima paliçádico, uma vez que no subosque ocorre preferencialmente luz difusa. O parênquima esponjoso é mais eficiente na distribuição da luz difusa no interior da folha do que as células do parênquima paliçádico, devido à trajetória aleatória da luz dentro deste tecido (Vogelmann et al. 1996, Smith et al. 1997). Em ambientes com menor intensidade luminosa, a ocorrência da relação espessura do parênquima esponjoso/espessura do parênquima paliçádico > 1 torna-se vantajosa como um mecanismo de otimização de captura de luz (Vogelmann et al. 1996, Taiz \& Zeiger
2004). A relação esponjoso/paliçádico $>1$ ocorreu nas folhas de FOM $(1,58 \pm 0,44)$, EGL $(1,28 \pm 0,43)$ e FODAM $(2,30 \pm 0,52)$, enquanto que em FODM a relação é de $0,97 \pm 0,15$. Tais valores para as folhas de FOM e FODM parecem resultar da variação da intensidade luminosa no interior da floresta e da menor espessura da lâmina.

As menores densidades de estômatos por unidade de área das folhas da FOM e FODM provavelmente são uma resposta à maior disponibilidade de água e umidade destes locais permitindo desta forma que os estômatos permaneçam abertos por mais tempo (Fahn \& Cutler 1992, Dickison 2000). Os valores mais altos de AFE nas folhas de FOM e FODM indicam um maior grau de mesofilia, segundo os critérios de Marin e Medina (1981). O grau de mesofilia, devido à maior área foliar e menor espessura da lâmina, é maior nas folhas de FOM do que nas folhas da FODM. Apesar das folhas da FODM e FOM apresentarem características mais mesomórficas, ocorrem diferenças quantitativas que diferenciam as folhas destas duas fitofisionomias. A FOM apresenta maior umidade relativa do ar e maior fertilidade do solo do que a FODM. Estas características ambientais diferenciadas provavelmente são determinantes na variação da estrutura foliar encontrada entre as folhas destas duas florestas.

Na EGL e FODAM, a alta intensidade luminosa associada às condições de solo caracterizam estas fitofisionomias como ambientes mais xéricos. Os indivíduos destas fitofisionomias são de pequeno porte, não formam densos agrupamentos, recebendo intensa radiação solar durante o dia. O solo (neossolo litólico) de ambos locais se caracteriza por ser extremamente raso, com pequena capacidade de retenção de água (tabela 1), principalmente quando se situa em topo de paisagem sobre contato lítico, como na FODAM. Apesar da pluviosidade ser alta (tabela 1), a baixa retenção de água do solo impõe estresse hídrico às plantas na maior parte do ano. Assim, as folhas dos indivíduos de M. sellowiana que ali se desenvolvem apresentam caracteres mais xeromóficos do que as folhas dos indivíduos das demais fitofisionomias estudadas.

Consequientemente, as folhas de M. sellowiana de EGL e FODAM possuem menores áreas foliares, massas secas e AFEs, maiores densidades estomáticas e de tricomas da face abaxial, maiores espessuras da cutícula da face adaxial, do parênquima esponjoso e espessura total.

Folhas menores são favoráveis para plantas sob intensa luminosidade porque diminuem a resistência da camada limítrofe que por sua vez influencia na 
transferência de calor entre a folha e a atmosfera (Jurik et al. 1982, Turner 2001, Taiz \& Zeiger 2004), evitam a transpiração excessiva em ambientes com intensa luz solar e conseqüentemente maior temperatura (Lewis 1972, Fahn \& Cutler 1992, Turner 2001) ou ainda podem ser consideradas como uma resposta das plantas que se desenvolvem em solos com baixo suprimento de água (Groom \& Lamont 1997, Noda et al. 2004) e baixa capacidade de reter e manter nutrientes (Turner 1994, Bussoti et al. 2000) como são os solos da EGL e FODAM. A influência que os fatores externos exercem sobre a planta é menor quanto menor for sua área exposta. Portanto, em ambientes xéricos, a redução da área de transpiração e a presença de características que aumentem a refletância são ecologicamente vantajosas (Lewis 1972, Gutschick 1999).

As maiores quantidades de estômatos e tricomas, por unidade de área, parecem ser uma estratégia de conservação de água das folhas que se desenvolvem em condições mais xéricas (Körner et al. 1986), pois o maior número de estômatos permite troca de gases mais eficaz nos curtos períodos do dia em que a umidade relativa do ar é maior e as taxas de transpiração mais baixas (Allen $\&$ Pearcy 2000). O maior número de tricomas encontrados nas folhas de EGL, além de refletir os raios solares, principalmente os ultra-violeta que podem danificar o aparato fotossintético (Smith et al. 1997, Press 1999), diminuem a temperatura foliar, evitando a perda de água por transpiração, durante o dia, e mantém a temperatura dos tecidos acima da temperatura do ar, durante a noite (Woodman \& Fernandes 1991, Press 1999). A cutícula da face adaxial mais espessa nas folhas da EGL e FODAM forma uma barreira hidrofóbica para prevenção da folha contra a perda de vapor de água (Hlwatika \& Bhat 2002) e aumenta a reflexão da luz incidente (Chazdon \& Kaufmann 1993) para minimizar o excesso de irradiação solar sobre os tecidos subjacentes (Fahn \& Cutler 1992).

As maiores espessuras e/ou maior número de estratos de parênquima paliçádico e esponjoso, em folhas sob alta intensidade luminosa, são relacionadas diretamente com aumento das atividades fotossintéticas (Thompson et al. 1992, Strauss-Debenedetti \& Berlyn 1994) e refletem nas maiores espessuras das lâminas foliares encontradas em EGL e FODAM. O parênquima paliçádico mais espesso facilita o trajeto da luz canalizada no interior da folha, permitindo taxas mais uniformes de fotossíntese (Vogelmann et al. 1996).

Os menores valores de AFE nas folhas de EGL e FODAM indicam um maior grau de esclerofilia, segundo os critérios de Marin e Medina (1981). Estes resultados corroboram alguns estudos que relacionaram a AFE com vários fatores com intensidade de luz, indicando que as folhas expostas a altas intensidades luminosas (Edwards et al. 2000, Kun-Fang 2000, Mendes et al. 2001) assim como aquelas que se desenvolveram em solos com baixa retenção de água e concentração de nutrientes (Meziane \& Shipley 1999, Navas \& Garnier 2002), como o solo da EGL e FODAM, possuem maior grau de esclerofilia. Entretanto, é importante ressaltar que existem diferenças ambientais entre EGL e FODAM (tabela 1) e que estas se manifestam através das diferenças estruturais encontradas nas folhas destas duas fitofisionomias.

Utilizando-se o PC1 e os valores médios da área foliar, massa seca, densidade estomática e espessura do parênquima esponjoso (Turner 1994) é possível estabelecer um gradiente de mesofilia/xeromorfia entre as quatro fitofisionomias: $F O M>F O D M>E G L>F O D A M$. Este gradiente reflete as variações estruturais da folha em resposta as diferenças ambientais, apesar da similaridade de solo e clima entre os locais (FOM/FODM e EGL/FODAM). Estudos similares com folhas de Erythroxylum ovalifolium em três sítios também indicaram um gradiente de xeromorfia em função do regime de pluviosidade e estrutura da vegetação (Mantuano et al. 2006).

Os resultados obtidos mostraram que algumas características morfológicas apresentaram um maior grau de plasticidade como área e massa foliar, densidade estomática e espessura do parênquima esponjoso, gerando diferentes padrões morfológicos. Apenas uma característica não apresentou variação morfológica (espessura da cutícula da epiderme abaxial), enquanto que as demais variaram, em termos de plasticidade, entre as fitofisionomias estudadas. Essa diversidade morfológica encontrada em M. sellowiana possibilita que essa espécie cresça em diferentes ambientes, desenvolvendo várias estratégias para se desenvolver mesmo quando as condições ambientais se apresentam mais desfavoráveis. Entretanto, a maioria das espécies de Melastomataceae não apresentam tal variabilidade morfológica e, geralmente, possuem preferência clara por determinados ambientes. A ocorrência de espécies com distribuição restrita é alta (cerca de 60\%, no estado), assim como os endemismos são muito freqüentes na família (Goldenberg 2004).

Assim, pode-se inferir que a variabilidade morfológica observada em M. sellowiana é uma vantagem adicional da espécie, uma vez que a interação entre a heterogeneidade ambiental e a plasticidade permite que as plantas explorem novos nichos em busca de recursos e ampliem suas possibilidades de distribuição, 
principalmente em ambientes mais heterogêneos (Cardoso \& Lomônaco 2003; Sultan 2003).

Agradecimentos - Os autores agradecem ao CNPq que forneceu as bolsas de Mestrado para R.M. Gluzezak, de produtividade para R. Goldenberg e de Iniciação Científica para M.W. Pil e a Dra. Celina Wisniewski pela classificação do solo.

\section{Referências bibliográficas}

ALLEN, M.T. \& PEARCY, R.W. 2000. Stomatal behavior and photosynthetic performance under dynamic light regimes in a seasonally dry tropical rain forest. Oecologia 122:470-478.

BUSSOTTI, F., BORGHINI, F., CELESTI, C., LEONZIO, C. \& BRUSCHI, P. 2000. Leaf morphology and macronutrients in broadleaved trees in central Italy. Trees 14:361-368.

CÁCERES, N.C. 2004. Occurrence of Conepatus chinga (Molina) (Mammalia, Carnivora, Mustelidae) and other terrestrial mammals in the Serra do Mar, Paraná, Brazil. Revista Brasileira de Zoologia 21:577-579.

CARDOSO, G.L. \& LOMÔNACO, C. 2003. Variações fenotípicas e potencial plástico de Eugenia calycina Cambess. (Myrtaceae) em uma área de transição cerrado-vereda. Revista Brasileira de Botânica 26:131140.

CHAZDON, R.L. \& KAUFMANN, S. 1993. Plasticity of leaf anatomy of two rain forest shrubs in relation to photosynthetic light acclimation. Functional Ecology 7:385-394.

DICKISON, W.C. 2000. Integrative plant anatomy. Harcourt Academic Press, San Diego.

DONHA, A.G. 2003. Avaliação do uso de técnicas de suporte à decisão na determinação da fragilidade em ambiente de geoprocessamento: o caso do Centro de Estações Experimentais do Canguiri. Dissertação de mestrado, Universidade Federal do Paraná. Curitiba.

EDWARDS, C., READ, J. \& SANSON, G. 2000. Characterising sclerophylly: some mechanical properties of leaves from heath and forest. Oecologia 123:158-167.

EMBRAPA. 1999. Sistema brasileiro de classificação de solos. Empresa Brasileira de Pesquisa Agropecuária, Centro Nacional de Pesquisa de Solos, Rio de Janeiro.

FAHN, A. \& CUTLER, D.F. 1992. Xerophytes. Gebrüder Borntraeger, Berlin.

FUZETO, A.P. \& LOMÔNACO, C. 2000. Potencial plástico de Cabraela canjerana subsp. polytricha (Adr. Juss.) Penn. (Meliaceae) e seu papel na formação de ecótipos em área de cerrado e vereda. Revista Brasileira de Botânica 23:169-176.

GOLDENBERG, R. 2004. O gênero Miconia (Melastomataceae) no Estado do Paraná. Acta Botanica Brasilica 18:927947.
GROOM, P.K. \& LAMONT, B. 1997. Xerophytic implications of increased sclerophylly: interactions with water and light in Hakea psilorrhyncha seedlings. New Phytologist 136:231-237.

GUTSCHICK, V.P. 1999. Biotic and abiotic consequences of differences in leaf structure. New Phytologist 143:3-18.

HAMMER, Ø., HARPER, D.A.T. \& RYAN, P.D. 2001. PAST: Paleontological statistics software package for education and data analysis. Palaeontologia Electronica 4:1-99.

HLWATIKA, C.N.M. \& BHAT, R.B. 2002. An ecological interation. Annals of Botany 89:109-114.

IBGE - Instituto Brasileiro de Geografia e Estatística. 1992. Manual técnico da vegetação brasileira. Série Manuais Técnicos em Geociências. № 1. $1^{\text {a }}$ ed, Rio de Janeiro.

JURIK, T.W., CHABOT, J.F. \& CHABOT, B.F. 1982. Effects of light and nutrients on leaf size, $\mathrm{CO}_{2}$ exchange, and anatomy in wild strawberry (Fragaria virginiana). Plant Physiology 70:1044-1048.

KLEIN, R.M. 1984. Aspectos dinâmicos da vegetação do sul do Brasil. Sellowia 36:5-54.

KÖRNER, C., BANNISTER, P. \& MARK, A.F. 1986. Altitudinal variation in stomatal conductance, nitrogen content and leaf anatomy in different plant life forms in New Zealand. Oecologia 69:557-588.

KUN-FANG, C. 2000. Leaf anatomy and chlorophyll content of 12 woody species in contrasting light conditions in a Bornean Heath Forest. Canadian Journal of Botany 78:1245-1253.

LEWIS, M.G. 1972. The physiological significance of variation in leaf structure. Science Progress 60:25-51.

MANTUANO, D.G., BARROS, C.F. \& SCARANO, F.R. 2006. Leaf anatomy variation within and between three "restinga" populations of Erythroxylum ovalifolium Peyr: (Erythroxylaceae) in Southeast Brazil. Revista Brasileira de Botânica 29:209-215.

MARIN, D. \& MEDINA, E. 1981. Duracion foliar, contenido de nutrientes y esclerofilia en arboles de un bosque muy seco tropical. Acta Cientifica Venezoelana 32:508-514.

MARQUES, A.R., GARCIA, Q.S. \& FERNANDES, G.W. 1999. Effects of sun and shade on leaf structure and sclerophylly of Sebastiania myrtilloides (Euphorbiaceae) from Serra do Cipó, Minas Gerais, Brazil. Boletim Botânico 18:21-27.

MARQUES, A.R., GARCIA, Q.S., REZENDE, J.L.P. \& FERNANDES, G.W. 2000. Variations in leaf characteristics of two species of Miconia in the Brazilian cerrado under different light intensities. Tropical Ecology 41:47-60.

MENDES, M.M., GAZARINI, L.C. \& RODRIGUES, M.L. 2001. Acclimation of Myrtus communis to contrasting Mediterranean light environments-effects on structure and chemical composition of foliage and plant water relations. Environmental and Experimental Botany 45:165-178. 
MEZIANE, D. \& SHIPLEY, B. 1999. Interacting determinants of specific leaf area in 22 herbaceous species: effects of irradiance and nutrient availability. Plant Cell and Environment 22:447-459.

NAVAS, M.L. \& GARNIER, E. 2002. Plasticity of whole plant and leaf traits in Rubia peregrina in response to light, nutrient and water availability. Acta Oecologica 23:375-383.

NODA, H., MURAOKA, H. \& WASHITANI, I. 2004. Morphological and physiological acclimation responses to contrasting light and water regimes in Primula sieboldii. Ecological Research 19:331-340.

O'BRIEN, T.P. \& MCCULLY, Y.E. 1981. The study of plants structure: principles and selected methods. Termercarphy, Melbourne.

PRESS, M.C. 1999. The functional significance of leaf structure: a search for generalizations. New Phytologist 143:213-219.

SARAIVA, L.C., CESAR, O. \& MONTEIRO, R. 1996. Breeding systems of shrubs and trees of a Brazilian savanna. Arquivos de Biologia e Tecnologia 39:751-763.

SCHLICHTING, C.D. 2002. Phenotypic plasticity in plants. Plant Species Biology 17:85-88.

SMITH, W.K., VOGELMANN, T.C., DELUCIA, E.H., BELL, D.T. \& SHEPHERD, K.A. 1997. Leaf form and photosynthesis: do leaf structure and orientation interact to regulate internal light and carbon dioxide? Bioscience 47:785-793.

STRAUSS-DEBENEDETTI, S. \& BERLYN, G.P. 1994. Leaf anatomical responses to light in five tropical Moraceae of different successional status. American Journal of Botany 81:1582-1591.
SULTAN, S.E. 2003. Phenothypic plasticity in plants: a case study in ecological development. Evolution and Development 5:25-33.

SWIECH-AYOUB, B.P. \& MASUNARI, S. 2001. Flutuações de Aegla castro Schmitt (Crustacea, Anomura, Aeglidae) no Buraco do Padre Ponta Grossa, Paraná, Brasil. Revista Brasileira de Zoologia 18:1003-1017.

TAIZ, L. \& ZEIGER, E. 2004. Fisiologia vegetal. Artmed, Porto Alegre.

THOMPSON, W.A., KRIEDEMANN, P.E. \& CRAIG, I.E. 1992. Photosynthetic response to light and nutrients in sun-tolerant and shade-tolerant rainforest trees. I. Growth, leaf anatomy and nutrient content. Australian Journal of Plant Physiology 19:1-18.

TURNER, I.M. 1994. A quantitative analysis of leaf form in woody plants from the word's major brodleaved forest types. Journal of Biogeography 21:413-419.

TURNER, I.M. 2001. The ecology of trees in the tropical rain forest. Cambridge University Press, New York.

VELOSO, H.P., RANGEL, L.R.Fo . \& LIMA, J.C.A. 1991. Classificação da vegetação brasileira, adaptada a um sistema universal. IBGE, Rio de Janeiro.

VIA, S. \& LANDE, R. 1985. Genotype-environment interations and the evolution and the evolution of phenotypic plasticity. Evolution 39:505-522.

VOGELMANN, T.C., NISHIO, J.N. \& SMITH, W.K. 1996. Leaves and light capture: light propagation and gradients of carbon fixation within leaves. Trends in Plant Science 1:65-70.

WOODMAN, R.L. \& FERNANDES, G.W. 1991. Differential mechanical defence: herbivory, evapotranspiration, and leaf hairs. Oikos 60:11-19. 